\title{
Microencapsulation of Calamansi (Citrus Microcarpa) Essential Oil onto $\beta$-Cyclodextrin for Cotton Fabric Application
}

\author{
Geraldine S Fernandez, Anilyn M Falcatan*, Lynne M Labaclado and Aileen I Atienza
}

College of Science, University of the City of Manila, Philippines

*Corresponding author: Anilyn M Falcatan, College of Science, University of the City of Manila, Intramuros, Manila, Philippines.

\begin{abstract}
Microencapsulation in textiles is a cost effective and long-lasting method in storing volatile substances over a long period of time which can be used for several applications such as antimicrobial textiles.

In this study, coprecipitation method was used for the microencapsulation of calamansi essential oil (guest molecule) in $\beta$-cyclodextrin (wall material) using 1,2,3,4-butanetetracarboxylic acid as crosslinker. The microcapsules were characterized using Scanning Electron Microscopy (SEM) and Fourier Transform Spectroscopy (FTIR), and Differential Scanning Calorimetry (DSC) before incorporated onto the scour-bleached cotton fabric using pad-dry-cure method. The developed cotton fabrics were further characterized using SEM and FTIR.

The mass ratio of 3:1 ( $\beta$-cyclodextrin to oil) with constant stirring time of 8 hours obtained the highest microencapsulation yield of $72.03 \%$. SEM micrographs revealed that the synthesized microcapsules were tiny cube- liked in structure. The FTIR spectra of the microcapsule showed similar peaks with $\beta$-cyclodextrin and no peaks similar with the calamansi oil, indicating the successful encapsulation of the guest molecule with the wall material. The DSC thermograms further showed evidence for the encapsulation. The successful incorporation of the microcapsules onto the cotton fabric was evidenced in the SEM micrographs while FTIR confirmed the crosslinking through butane tetracarboxylic acid with a peak at 1714 cm-1 that did not appear on the untreated fabric. This showed an ester carbonyl bond that may have formed between the fabric and microcapsule.
\end{abstract}

Keywords: : Microencapsulation; Microcapsule; Cotton fabric; Calamansi essential oil; $\beta$-cyclodextrin

\section{Introduction}

The primary requirements for human beings to live comfortably and work with maximum efficiency is health and hygiene. This may cover the textiles used as clothing. Cotton textiles in contact with human body can promote the growth of microorganisms which may lead to biodeterioration and spread of diseases. Biodeterioration is any undesirable change in the properties of a material which may lead to disgusting smell even from inner apparel such as socks and underwear [1,2]. Clothes worn by health care workers are even more susceptible since these can be easily contaminated in the en vironment they are working on. A study showed that microbes can survive for at least 1 day while some can survive for more than 90 days on clothing [3].

In order to minimize this problem, many studies focused on developing ways to lessen the propagation of these microbes in textiles. The use of antimicrobial agents such as titanium dioxide has gained interest. However, such material is expensive, synthetic-based and may not be environment-friendly [4]. So, some researchers are finding natural products as an alternative source of 
this antibacterial property that can be applied to textiles. Examples of these are plant extracts and essential oils.

Essential oils can be applied in fabric through microencapsulation. Microencapsulation is a process in which tiny particles or droplets are surrounded by a coating to give small capsules of many useful properties. Microcapsules can be applied to textile by padding, coating, spraying or immersion. A wall material is needed which protects the guess molecule from the environment. Some of these wall materials are chitosan, urea formaldehyde, xanthan, $\beta$ - cyclodextrin, etc. Among the three types of cyclodextrin, $\beta$-cyclodextrin is the most accessible, the lowest-priced and generally the most useful [5].

In this current research, the essential oil of calamansi (Citrus microcarpa) was encapsulated with $\beta$-cyclodextrin and applied to cotton fabric for possible antimicrobial textile application. Calamansi essential oil was found to have active antimicrobial activity against one or more species of bacteria [6]. However, essential oils are volatile and vaporize readily in the air. Microencapsulation techniques can be used to enhance the durability and control the release on the oil.

\section{Materials and Methods}

\section{Synthesis of $\beta$-cyclodextrin mixture}

Co-precipitation is the method used in synthesizing microcapsules. This method was adopted from the method of microencapsulation stated by Hirayama and Uekama [7]. Solutions of $\beta$-cyclodextrin (Sigma-Aldrich) to calamansi essential oil mass ratios of 1:1, 2:1 and 3:1 were made. The calamansi essential oil served as the guest molecule while $\beta$-cyclodextrin was used as the wall material. The required amount of $\beta$-cyclodextrin needed in $200 \mathrm{ml}$ distilled water was first dissolved while heating to $55{ }^{\circ} \mathrm{C}$. Then the required amount of calamansi oil was added in the solution. This was heated and stirred for 4 hours and another set for 8 hours. Afterwards, the mixtures were cooled to room temperature and filtered. The filter papers were put inside the petri dishes and stored in a desiccator until the microcapsule dried. The microencapsulation yield was determined using equation 1 .

$\%$ yield $=\frac{\text { Mass of microcapsules after drying }}{\text { Initial amount of cyclodextrin and oil }} \times 100$

The obtained microcapsules were placed inside amber bottles and stored in a desiccator.

\section{Characterization of the microcapsule}

Scanning Electron Microscopy (SEM) was used to examine the morphology and size of the microcapsule. Fourier Transform Infrared - Attenuated Total Reflectance (FTIR-ATR) Spectroscopy of the microcapsule together with the pure cyclodextrin and essential oil was also used for characterizing the functional groups present on the samples. Analysis under Differential Scanning Calorimetry (DSC) was also done to confirm the linkage between calamansi oil and $\beta$-cyclodextrin.

\section{Grafting of $\beta$-Cyclodextrin microcapsule onto the fabric}

The scour-bleached cotton fabrics was soaked in a solution of $\beta$ -cyclodextrin microcapsule and 1,2,3,4- butane tetracarboxylic acid (BTCA) (Sigma-Aldrich) having a 1:2 mass ratio for 1 hour, while the $\mathrm{pH}$ of solution was held constant between 2 to 3 . Butane tetracarboxylic acid served as the cross-linker. The sample was padded through a pneumatic padding mangle under $1 \mathrm{~kg} / \mathrm{cm}^{2}$ to obtain a wet pick up of $90-100 \%$. The wet pick up was determined using equation 2. Lastly, the sample was dried using the drying oven at 50 ${ }^{\circ} \mathrm{C}$ for 5 minutes and was cured using the curing oven at $80^{\circ} \mathrm{C}$ for 3 minutes. After drying, the sample was placed in a ziplock and stored in a desiccator.

$$
\% \text { wet pickup }=\frac{\text { Wet weight }- \text { Original weight }}{\text { Original weight }} \times 100
$$

For the characterization of the applied microcapsules in the cotton fabric, SEM was used to show the morphology of adhesion of microcapsules onto the cotton fabric. FTIR was also used to examine whether the microcapsules adhered on the fabric by means of cross-linking.

\section{Results and Discussion}

\section{Synthesis of $\beta$-Cyclodextrin microcapsules}

Different mass ratios of $\beta$-cyclodextrin to oil microcapsules (Table 1) were made via co-precipitation method. The solutions were constantly stirred and heated up to the range of temperature 50-55 ${ }^{\circ} \mathrm{C}$ to speed up the dissolution process. The solution became clearer as the temperature reached the range of temperature. As the calamansi oil was added, the solution eventually turned from colorless to cloudy white.

It was observed in the $1: 1 \beta$-cyclodextrin to oil mass ratio, the microcapsules formed slowly as an oily layer formed. After drying the samples, they turned into light yellow in color. This indicates that there were some essential oils not encapsulated by the $\beta$-cyclodextrin. The sample with the 3:1 mass ratio was the most similar in appearance to the pure $\beta$-cyclodextrin.

Table 1 shows that the amount of encapsulated oil increased as the amount of $\beta$-cyclodextrin increased. It can also be observed that there is a very small percentage yield obtained in $1: 1$ ratio. This yield gives an idea about the encapsulation efficiency by the co-precipitation method. Loss of oil could be accounted for this since there was an oily layer appeared in the flask after the hours of stirring. It was also observed during the experiment that the more $\beta$ - cyclodextrin dissolved in water, the faster the microcapsules formed as the oily layer disappeared. The lowest microencapsulation yield was the microcapsules having a sample label of 1:1(8) with $19.05 \%$ percent yield and the highest microencapsulation yield was the microcapsules having a label of 3:1(4) with $72.03 \%$ percent yield. 
Table 1: Parameters and conditions for the synthesis of $\beta$-cyclodextrin-oil microcapsules.

\begin{tabular}{|c|c|c|c|c|c|}
\hline Sample Label $^{1}$ & Mass of $\beta$ - cyclodextrin (g) & Mass of calamansi oil (g) & Stirring time (hours) & Mass of precipitate $(\mathrm{g})^{2}$ & $\%$ yield $(n=5)$ \\
\hline $1: 1(4)$ & 1.005 & 1.0141 & 4 & 0.5985 & 29.64 \\
\hline $2: 1(4)$ & 2.0021 & 1.0226 & 4 & 1.8065 & 59.72 \\
\hline $3: 1(4)$ & 3.0018 & 1.008 & 4 & 2.8881 & 72.03 \\
\hline $1: 1(8)$ & 1.0025 & 1.0055 & 8 & 0.3825 & 19.05 \\
\hline $2: 1(8)$ & 2.0026 & 1.0234 & 8 & 1.8065 & 59.7 \\
\hline $3: 1(8)$ & 3.0046 & 1.038 & 8 & 2.8856 & 71.38 \\
\hline
\end{tabular}

${ }^{1}$ Sample Label, the number stands for the $\beta$-cyclodextrin-oil mass ratios and stirring time, respectively

${ }^{2}$ Dry basis

Since the 3:1 was the optimum mass ratio for encapsulation, time. Four (4) hours and eight (8) hours stirring time durations this was used to study the morphology on the different stirring were used.

\section{Characterization}

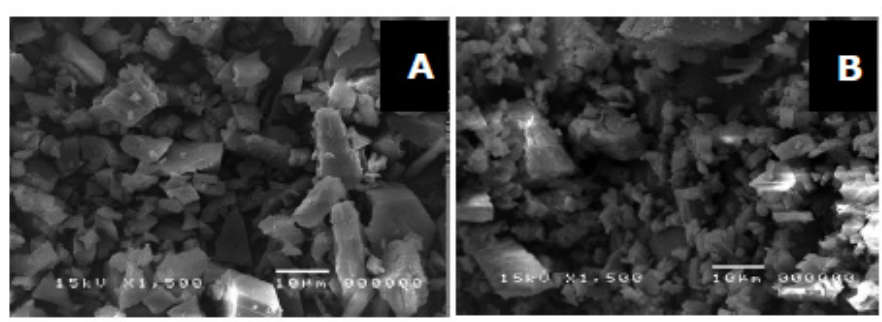

Figure 1: SEM Micrographs of microcapsules (A) 3:1-4 hours (B) 3:1-8 hours, 1500x magnification.

Scanning electron microscopy: Figure 1 shows the SEM micrographs of the synthesized microcapsules at different stirring times. In the 4 hours stirring time, the microcapsules formed were larger compared to the microcapsules formed in 8 hours stirring time. Cubed-like shapes are seen in the micrographs. According to Mukhopadhyay, microcapsules are not limited to spherical shape and may have regular or irregular forms [8].

The SEM images show smaller microcapsules formed at longer stirring time. Larger microcapsules were found to rupture more easily than smaller ones in the previous study [9]. This means smaller microcapsules have better retention of guest molecules. Therefore, the optimum stirring time was chosen as 8 hours.

Fourier transform infrared spectroscopy: Small amounts of the pure $\beta$-cyclodextrin, pure calamansi oil and $\beta$-cyclodextrin-oil microcapsules were subjected to FTIR at the Philippine Nuclear Research Institute. This was done to identify the functional groups present on the $\beta$-cyclodextrin-oil microcapsules and compare the functional groups present on the pure calamansi oil and pure $\beta$ - cyclodextrin.

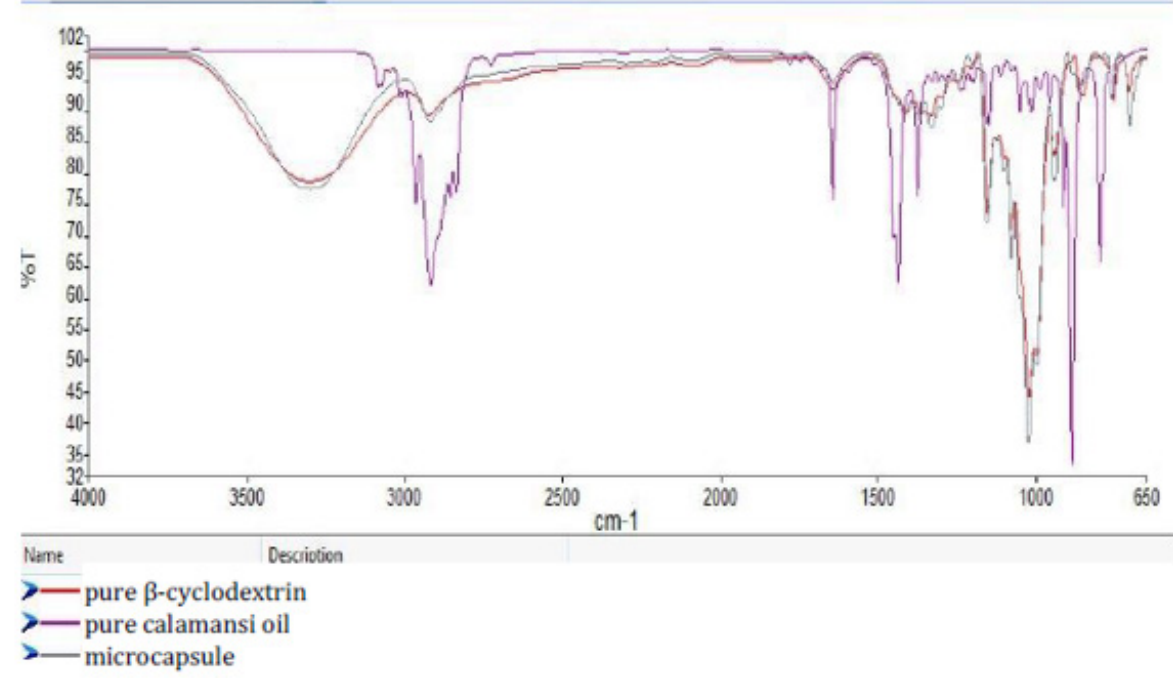

Figure 2: FTIR Spectra of pure $\beta$-cyclodextrin, pure calamansi oil and the $\beta$-cyclodextrin-oil microcapsule. 
As seen in Figure 2, the spectrum of the synthesized microcapsules is the same with that of the pure $\beta$-cyclodextrin. There are broad peaks found at around $3300 \mathrm{~cm}^{-1}$ for both microcapsule and pure $\beta$-cyclodextrin which is absent in the pure calamansi. These peaks confirm the presence of $-\mathrm{OH}$ bonds. There are also peaks found at around $3000 \mathrm{~cm}-1$ for all the samples which indicate $-\mathrm{CH}$ bonds and further shows that the functional groups were mostly aliphatic groups [10].

In the fingerprint region, regardless of the intensity, the peaks found in the pure $\beta$-cyclodextrin and the synthesized microcapsules are almost similar and no peaks of calamansi oil is found in the spectra. This indicates that the calamansi oils were encapsulated.

Differential scanning calorimetry: Samples of pure $\beta$-cyclodextrin, pure calamansi oil and $\beta$-cyclodextrin-oil microcapsules were submitted to University of Santo Tomas -Analytical Service Laboratory for Differential Scanning Calorimetry analysis.
Every sample was heated from $25^{\circ} \mathrm{C}$ to $300{ }^{\circ} \mathrm{C}$ at a rate of $10{ }^{\circ} \mathrm{C} / \mathrm{min}$.

Differential scanning calorimetry is a routine method, commonly used to verify the formation of a complex in the solid state [11]. This analysis is mainly used to validate the complex formation between the guest molecule and the wall material. The total or partial disappearance of thermal events (melting point) corresponding to guest molecules is generally taken as a proof of complex formation [12]. As shown in Figure 3, the peaks found on the pure $\beta$-cyclodextrin and pure calamansi oil can't be found on the peaks of microcapsules and this serves as evidence of the complex formation

\section{Grafting of the microcapsules onto the cotton fabric}

Scour-bleached cotton fabrics were immersed in the solution of microcapsules with 1,2,3,4-butanetetracarboxylic acid (BTCA) having a mass ratio of 1:2 (microcapsule: BTCA). Table 2 shows $\%$ wet pick up of the fabric before grafting the microcapsules.

Table 2: Wet pick up of the fabric before grafting the microcapsules.

\begin{tabular}{|c|c|c|c|c|c|}
\hline \multirow{2}{*}{ Sample label ${ }^{1}$} & \multirow{2}{*}{ Mass of BTCA (g) } & \multirow{2}{*}{ Mass of microcapsule (g) } & \multicolumn{2}{|c|}{ Mass of fabric (g) } & \multirow{2}{*}{$\begin{array}{c}\text { Wet pick up (\%) } \\
(n=5)\end{array}$} \\
\hline & & & Before (dry) & After (wet) & \\
\hline CF (1:2) & 10 & 5 & 10.3029 & 19.8826 & 92.98 \\
\hline
\end{tabular}

'Sample label- CF corresponds to cotton fabric and the number corresponds to the ratio of microcapsule to BTCA

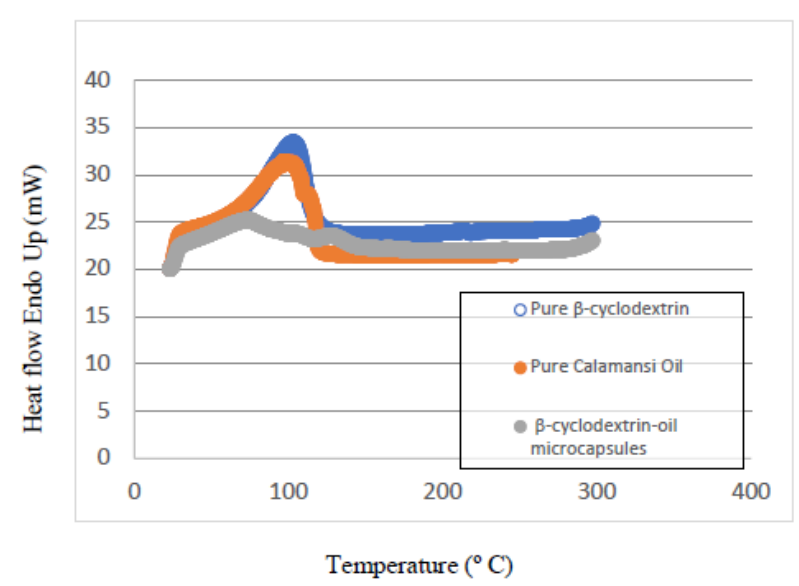

Figure 3: DSC thermograms of pure $\beta$-cyclodextrin, pure calamansi oil and $\beta$-cyclodextrin-oil microcapsules.

The SEM micrographs of the untreated fabric showed a great difference with the treated fabric. Shown in Figure 4, the microcapsules adhered on the surface of the cotton fabric. However, this micrograph does not specify whether the microcapsules have adhered by means of crosslinking. Thus, characterization using FTIR analysis was also done.
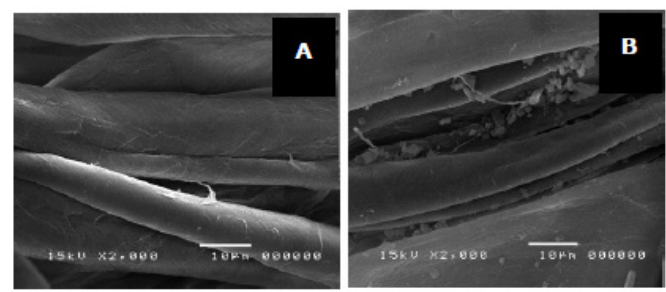

Figure 4: SEM micrographs of cotton fabric (A) untreated (B) treated. 
As shown in Figure 5, there is a peak around $1700 \mathrm{~cm}^{-1}$ for the treated cotton fabric which does not appear on the untreated fabric. This is an ester carbonyl peak that shows evidence of cross-link- ing. The appearance of the fabric itself can be an evidence for the cross-linking; the color turns into yellowish from white.

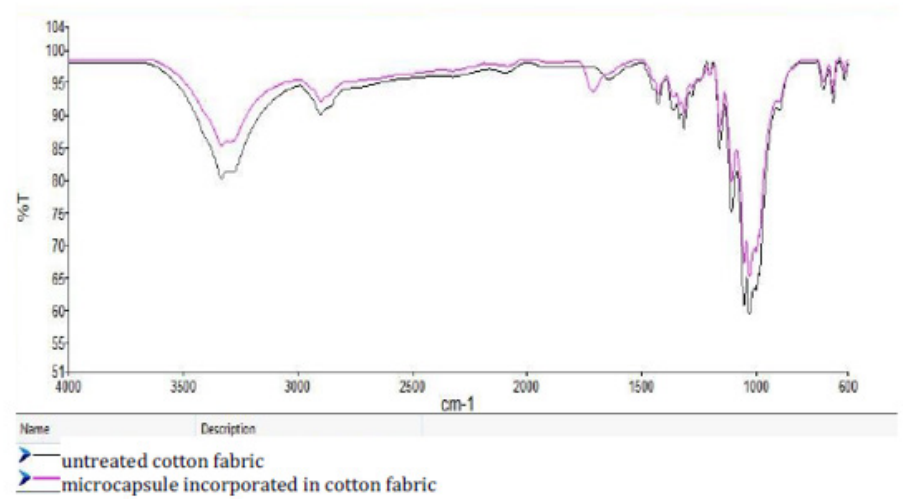

Figure 5: FTIR spectra of untreated vs. treated cotton fabric.

\section{Conclusion}

Results showed successful microencapsulation of calamansi oil and grafting of the $\beta$-cyclodextrin microcapsule onto the cotton fabric. The optimum condition of synthesized microcapsules was determined to have a mass ratio of 3:1 ( $\beta$-cyclodextrin to oil) with constant stirring time of 8 hours and $72.03 \%$ microencapsulation yield. SEM micrographs revealed that the synthesized microcapsules were cube-liked in shape. The FTIR spectra of the microcapsule showed similar peaks with $\beta$-cyclodextrin and no peaks similar with the calamansi oil. The DSC thermograms showed evidence for the encapsulation of calamansi oil in $\beta$-cyclodextrin while SEM micrographs showed that microcapsules adhered on the surface of the cotton fabric. FTIR confirmed successful cross-linking using 1,2,3,4-butanetetracarboxylic acid.

\section{Acknowledgement}

None.

\section{Conflict of Interest}

Authors declare no conflict of interest.

\section{References}

1. Minocheherhomji F (2016) Microbial Interactions in Textile Industry: A Review. Int J Adv Res 4(8): 318- 321.

2. Boryo DE (2013) The Effect of Microbes on Textile Material: A Review on the Way-Out So Far. Int J Eng Sci 2(8): 9-13.
3. Neely AN, Maley MP (2000) Survival of Enterocci and Staphylococci on Hospital Fabric and Plastic. J Clin Microbiol 38(2): 724-726.

4. Sathianayanan MP, Bhat NV, Kokate SS, Walunj VE (2012) Antibacterial Finish for Cotton Fabric from Herbal Products. Indian J Fibre Text Res 35: 50-58.

5. Del Valle EM (2004) Cyclodextrins and their Uses: A Review. Process Biochem 39(9): 1033-1046.

6. Wei LS, Musa N, Sengm CT, Wee W, Shazili (2008) Antimicrobial Properties of Tropical Plants against 12 pathogenic Bacteria Isolated from Aquatic Organisms. Afr J Biotechnol 7(13): 2275-2278.

7. Hirayama, Uekama (1987) Methods of Investigating and Preparing Inclusion Compounds. Editions de Sante: Paris, pp. 131-172.

8. Mukhopadhyay HK, Halder T, Mohanraj P, Jasmina K (2011) Microencapsulation Techniques and Its Practice. Int J Res Pharm Sci Tech 6(2).

9. Coates J (2000) Interpretation of Infrared Spectra, A Practical Approach. In Encyclopedia of Analytical Chemistry; Meyers RA (edt) J Wiley: Chichester, U.K, pp. 10821-10822.

10. Long Y, Song K, York D, Zhang Z, Preece JA (2013) Engineering the Mechanical and Physical Properties of Organic-inorganic Composite Microcapsules. Colloids Surf Physicochem Eng Asp 433: 30-36.

11. Karathanos VT, Mourtzinos I, Yannakopoulou K, Andrikopoulos NK (2007) Study of the Solubility, Antioxidant Activity and Structure of Inclusion Complex of Vanillin with $\beta$-cyclodextrin. Food Chem 101(2): 652-658.

12. Pralhad T, Rajendrakumar K (2004) Study of Freeze-dried Quercetincyclodextrin Binary Systems by DSC, FT-IR, X-ray diffraction and SEM analysis. J Pharm Biomed Anal 34(2): 333-339. 